\title{
O livro didático de língua alemã no ensino superior brasileiro: análise de aspectos socioculturais e discursivos
}

\author{
The German textbook in Brazilian higher education: analysis of sociocultural \\ and discursive aspects
}

\author{
Cristiane Schmidt ${ }^{1}$ \\ Universidade Estadual do Oeste do Paraná
}

\begin{abstract}
- RESUMO: O processo de ensino e aprendizagem de línguas estrangeiras em âmbito institucionalizado remete à pertinência dos materiais didático-pedagógicos. Apesar da centralidade desses recursos, sobretudo do livro didático enquanto elemento institucionalizado nas aulas de línguas estrangeiras, as pesquisas com foco nesses materiais constituem-se incipientes. Considerando isso, o estudo apresenta um panorama do ensino de língua alemã como língua estrangeria em contexto brasileiro de formação docente, com base em dados levantados na pesquisa de Doutorado (UNIOESTE, 2016). Os objetivos visam (i) identificar os aspectos socioculturais presentes em três obras didáticas voltadas para aprendizes iniciantes, destacando em que medida contemplam a realidade linguística e sociocultural de outros contextos e (ii) analisar as vozes de professores/usuários de livros didáticos, no sentido de compreender em que medida seus discursos tem repercussão na constituição e no papel desses materiais. Como fundamentação teórica, o estudo dialoga com os pressupostos da Análise do Discurso e da Linguística Aplicada, estabelecendo relações com o objeto desta investigação. Os resultados evidenciam discursos distintos e similares por parte dos professores participantes da pesquisa. Como vozes discursivas convergentes, destaca-se a necessidade de adaptações nos livros didáticos, para adequação ao contexto sociolinguístico e cultural brasileiros.
\end{abstract}

- PALAVRAS-CHAVE: Análise do Discurso e Linguística Aplicada. Livro didático de língua alemã. Ensino superior brasileiro. Análise de aspectos socioculturais e discursivos.

- ABSTRACT: foreign languages teaching and learning process in an institutionalized context point to the relevance of didactic-pedagogical materials. In spite of the centrality of these resources, especially the textbook as an institutionalized element in foreign language classes, researches focusing on these materials are incipient. That said, this study presents a panorama of German teaching as a foreign language in a Brazilian context of teacher's development, based on data collected in the $\mathrm{PhD}$ research (UNIOESTE, 2016). The objectives are (i) to identify the sociocultural aspects present in three textbooks aimed at beginners, highlighting the extent to which they take into account the linguistic and sociocultural reality of other contexts, and (ii) to analyze the voices of professors/users of textbooks, to understand to what extent their discourse has repercussion on the constitution and the role of these materials. As theoretical foundation, the study dialogues with the presuppositions of Discourse Analysis and Applied Linguistics, establishing relations with the object of this investigation. The results show different and similar discourses on the part of the professors participating in the research. As converging discursive voices, the need for adaptations in textbooks is highlighted, in order to adapt to the Brazilian sociolinguistic and cultural context.

- KEYWORDS: Discourse Analysis and Applied Linguistics. German textbook. Brazilian higher education. Analysis of sociocultural and discursive aspects.

\footnotetext{
${ }^{1}$ Doutora em Letras pela UNIOESTE. Pós-doutoranda em Letras na UEMS/NEAD - Núcleo de Estudos em Análise do Discurso. Docente do Centro de Comunicação, Letras e Artes da UNIOESTE. cris lehrerin@hotmail.com
} 


\section{Introdução}

O ensino e a aprendizagem de língua e cultura estrangeiras em espaços institucionalizados, traz ao centro dos debates os recursos didático-pedagógicos, em especial o livro didático, sendo este concebido como um dos elementos mais característicos e, "por isso, já se institucionalizou, ou seja, apresenta-se como algo natural, que constitui o processo de educação" (PESSOA, 2009, p. 53).

E entende-se que na realidade brasileira sua presença seja ainda mais recorrente, visto ser um recurso essencial, constituindo-se, por vezes, no único material disponível no ensino e aprendizagem de idiomas. Ao mesmo tempo, esse material representa uma fonte de saber da língua e a cultura-alvos na educação básica e no ensino superior, assim como nos cursos de línguas. Com isso, o livro didático exerce considerável influência no que se ensina e como se ensina línguas.

Trabalhos recentes sobre o papel do livro didático de línguas estrangeiras mediando a prática pedagógica têm demonstrado que ele é um recurso de que dispõem professores e alunos para terem contato com a língua e a cultura estudadas; sendo que em alguns casos, ainda que esse material não esteja presente na mesa do aprendiz, é com base nele que os docentes baseiam suas aulas. Para Uphoff, os "materiais didáticos pressupõem, portanto, um certo modo de trabalho pedagógico e incentivam determinados processos de ensino do idioma" (UPHOFF, 2009, p. 55).

Sob o ponto de vista linguístico e discursivo, o livro didático pode ser concebido como um gênero complexo e multifacetado, conforme a perspectiva bakhtiniana $^{2}$, sendo constituído sociocultural e historicamente por uma rede complexa de relações e marcado por aspectos gráficos, editoriais e ideológicos. E por isso, não se pode desconsiderar o sistema de valores ideológicos implícitos nos materiais, nem o processo de socialização e aculturação do público a que se destina.

Considerando o exposto, este texto tratará da análise das vozes discursivas ${ }^{3}$ dos professores formadores - usuários de livros didáticos - quanto às concepções teóricometodológicas e ao papel desses materiais no ensino da língua alemã em âmbito universitário. Ao mesmo tempo, procurará tecer discussões sobre os aspectos socioculturais presentes em livros didáticos voltadas para aprendizes iniciantes, destacando em que medida contemplam a realidade linguística e sociocultural de outros contextos.

\section{Linguística Aplicada e Análise do Discurso: interfaces possíveis}

De uma parte, a língua nos pressupostos da Linguística Aplicada é compreendida com uma prática social, de modo que o contato e o estudo de uma língua (materna e estrangeira) requerem o estudo dos elementos externos ao fenômeno essencialmente linguístico. Trata-se da concepção de linguagem/língua, não como algo pronto para ser utilizado, mas algo constantemente renovado, visto ser a língua aqui

\footnotetext{
${ }^{2}$ Para Bakhtin (2003 [1979]), os gêneros do discurso são definidos como tipos relativamente estáveis de enunciado e apresentam três dimensões constitutivas: (i) o conteúdo temático, que consiste no objeto de discurso dizível por meio do gênero; (ii) o estilo, que diz respeito à seleção de recursos gramaticais, lexicais e fraseológicos; (iii) a construção composicional, que se refere à seleção de procedimentos composicionais para a organização verificada na estrutura dos textos pertencentes a um determinado gênero.

${ }^{3}$ Conforme a teoria polifônica de Bakhtin (2003[1979]), todo enunciado sendo essencialmente dialógico, remete a uma multiplicidade de vozes que podem ser ouvidas no mesmo lugar. Nesse sentido, o livro didático de ensino/aprendizagem de línguas, enquanto enunciado dialógico compreende a voz do destinatário que são os professores e os aprendizes de língua e para os quais o livro se organiza e se destina; e a voz do autor, a qual tem vinculação direta com assumir uma posição axiológica, uma vez que o autor é portador de um posicionamento valorativo que perpassa o livro didático do começo ao fim.
} 
entendida como uma atividade livre, criativa e de caráter dialógica. E, sobretudo, uma língua só tem existência e dinamicidade pelo fato de ser usada por sujeitos, os quais são constituídos por um determinado contexto sociocultural e histórico.

Von Borstel (2011), ressalta que por meio da linguagem a pessoa estabelece relações recíprocas de natureza linguística e cultural. Nesse sentido, a Linguística Aplicada sendo uma 'área de pesquisa que está diretamente relacionada à resolução de problemas práticos na realidade linguística da sociedade, pode contribuir muito para a área de ensino-aprendizagem de línguas" (VON BORSTEL, 2011, p. 2).

No cenário nacional, a Linguística Aplicada está se constituindo numa área de investigação relativamente estabelecida, na medida em que os estudos vêm se ampliando e se diversificando. No entendimento de Silva (2010), consta-se um aumento de pesquisas sobre materiais no ensino de línguas estrangeiras em Linguística Aplicada. Nas suas palavras "[...] é importante que pesquisas sobre livros didáticos de línguas estrangeiras no Brasil tenham constantes atenções, envolvendo professores que deverão usar os livros" (SILVA, 2010, p. 208). Ainda sobre a relevância de estudos com enfoque nos materiais de ensino de línguas estrangeiras, Pessoa afirma que:

[...] o uso do livro didático no ensino de línguas estrangeiras - sobretudo nos cursos de licenciatura - é uma das práticas que merecem ser analisadas, pois pode não só limitar as possibilidades de ação do professor, como também comprometer as próprias perspectivas de análise e compreensão do ensino, de suas finalidades educativas e de sua função social (PESSOA, 2009, p. 54).

Conforme Almeida Filho (2013), em todo e qualquer material didático subjaz um conceito, uma filosofia de ensino e uma abordagem de ensinar que também contempla um conceito de língua, de aprender línguas. Ao mesmo tempo, os materiais didáticos condensam uma expectativa de como devem proceder professores de línguas se quiserem, de fato, mediar com sucesso o aprender exitoso de quem já vai crescendo no seu poder de expressar e compreender os sentidos de uma língua-alvo em uso. Dessa forma, a seleção de material didático não deve ser intuitiva, sendo preciso que professores tenham o devido preparo através de reflexões e estudos.

De outra parte, a Análise do Discurso no contexto nacional também vem se constituindo numa área de investigação relativamente estabelecida, com pesquisadores renomados e estudos relevantes, sobretudo a partir da década de 1970, juntamente com o deslocamento da Linguística 'frasal' para a Linguística 'textual'. Com essa ruptura conceitual e metodológica, rompendo com uma tradição de vários séculos, o texto passa a ocupar a centralidade nos estudos linguísticos. Nesse aspecto reside a contribuição epistemológica da Análise do Discurso, pois para Orlandi, "ela se apresenta como uma teoria da interpretação no sentido forte" (ORLANDI, 2008, p. 21, grifo da autora).

Ainda para esse aporte teórico, o sentido do texto (oral/escrito) não está em abordar como informação, e sim a noção de efeitos de sentido, uma vez que vai se constituindo à medida que se constitui o próprio discurso. Assim, o sentido vai sendo determinado ao mesmo tempo em que as posições ideológicas vão sendo colocadas em jogo na relação entre as formações discursivas (POSSENTI, 2006).

Partindo do princípio de que a Análise do Discurso trabalha com o sentido, sendo o discurso heterogêneo marcado pela história e ideologia, essa teoria mostra como o discurso funciona não tendo a pretensão de dizer o que é certo, porque isso não está em julgamento. Ao mesmo tempo, essa perspectiva não considera como determinante a intenção dos sujeitos; mas entende que esses estejam condicionados por 
uma determinada ideologia que predetermina o que poderão dizer ou não em determinadas conjunturas histórico-sociais (MUSSALIM, 2006).

Conforme Orlandi (2002, p. 9) "a contribuição da análise do discurso para as outras áreas permite reflexão de que tudo que é exposto deve ser observado além dos signos e que devemos ter outro olhar para a linguagem acreditando no inacabado".

Nesse sentido, entende-se que os pressupostos da Linguística Aplicada e a Análise do Discurso são relevantes como suportes teórico-metodológicos para análise e a discussão dos dados deste estudo. É o que afirma Moita Lopes (2006) referindo-se à Linguística Aplicada na atualidade, que se encontra numa nova era e busca novos modos de teorizar.

De acordo com esse pesquisador (MOITA LOPES, 2006), a Linguística Aplicada utiliza-se não apenas dos conhecimentos teóricos produzidos pela Linguística, mas também procura estabelecer diálogo com as descobertas de uma variedade de campos dos saberes, portanto, visa transcender os limites disciplinares. Aqui também se defende um hibridismo teórico-metodológico, já que uma única área de investigação encontra dificuldades de entender um contexto globalizado, complexo e contraditório.

\section{Procedimentos metodológicos: ações e geração de dados}

A metodologia refere-se às visões de mundo e às concepções teóricas do pesquisador que, por sua vez, fundamentam o conjunto de procedimentos a serem empregadas na tessitura da pesquisa. A escolha da temática da análise dos elementos socioculturais e dos discursos de professores em contexto docente mediante adoção de livro didático de língua alemã tem relação direta com as vivências, as experiências e os pontos de vista advindas dessa prática. Logo, o paradigma de compreensão do objeto de estudo, implica uma natureza interpretativista-discursiva, em que a subjetividade é recorrente.

Além disso, a pesquisa qualitativa de caráter interpretativista e discursiva se justifica em decorrência da geração dos dados e dos sujeitos da pesquisa, a quem se privilegia a expressão de suas opiniões, seus desejos e sentimentos e os efeitos de sentido na materialidade do texto.

Especificamente em relação aos procedimentos metodológicos, determinadas ações foram adotadas para a geração dos dados e a compreensão do objeto de estudo, a saber:

(i) a quantificação dos cursos de formação de professores de língua alemã no contexto acadêmico atual, o contato com coordenadores e/ou professores da área de alemão e o levantamento dos livros didáticos adotados nessas instituições ${ }^{4}$;

(ii) a seleção do corpus da pesquisa, especificamente os três livros mais adotados nessas instituições contatadas;

(iii) o envio de questionário a docentes usuários dos livros didáticos ${ }^{5}$.

\footnotetext{
${ }^{4}$ Conforme o levantamento feito na pesquisa de Doutorado, no período de nov. 2015/abr. 2016, especificamente sobre a quantidade de cursos de Licenciatura em Letras/Alemão no contexto nacional, chegou-se ao número total de dezesseis (16) instituições, distribuídas entre as regiões Norte, Nordeste, Sudeste e Sul. Ao mesmo tempo, com esse diagnóstico, foi possível verificar que dentre o universo dessas universidades contatadas - quinze (15) adotam livros didáticos de ensino e de aprendizagem de língua alemã, atribuindo relevância e viabilizando esse estudo.

5 Vale destacar que essa ação consistiu no envio (no mês de junho de 2016 - via correio eletrônico) de um questionário (instrumento investigativo) a alguns professores participantes da pesquisa, convidando-os para darem sua avaliação sobre os livros didáticos empregados. Essa ação visa a identificação de posicionamentos, impressões e sentidos sobre esses materiais - um dos objetivos centrais do presente artigo.
} 
Entre alguns resultados das duas ações iniciais (i e ii), destaca-se que os dados revelam uma variedade de livros didáticos utilizados no ensino de língua alemã, somando dezessete (17) materiais distintos. Dentre dessa totalidade, as obras didáticas intituladas DaF kompakt, studio $d$ e Menschen são as que mais se evidenciaram no critério de pragmaticidade nos cursos de graduação (Licenciatura em Letras/Alemão).

Em outros termos, o livro DaF kompakt é adotado em seis cursos de formação de professores de língua alemã no ensino superior, seguido pelo material studio $d$ que apresenta cinco ocorrências. E o livro Menschen aparece como livro didático adotado em três cursos de graduação, assim se configura como material mais usado nos cursos extracurriculares (curso de línguas voltado exclusivamente para os acadêmicos) oferecidos nas instituições, contando com cinco ocorrências e, totalizando assim, oito ocorrências.

Tocante à ação seguinte (iii) que consiste em 'ouvir as vozes discursivas' de docentes/usuários desses livros didáticos, mediante o envio do instrumento investigativo intitulado 'Questionário - avaliação qualitativa do livro didático', reitera-se que compreende duas partes distintas, a saber:

$\mathrm{Na}$ primeira parte, constam algumas questões gerais referentes à identificação do professor participante: nome; formação profissional; tempo de atuação na área de língua alemã; nome do livro didático adotado; e tempo de adoção do livro pela instituição.

Na parte seguinte, encontram-se questões abertas que versam especificamente sobre o livro didático de ensino desse idioma. Essa parte do questionário contempla oito questões, as quais tratam de diversos aspectos, como conceito de livro didático, adequação do material à realidade sociolinguística e cultural do aprendiz brasileiro; motivação pela adoção do livro na instituição; vantagens e desvantagens no uso do livro didático, dentre outros aspectos que podem ser vistos no Apêndice 1.

Essa etapa da geração de dados, que compreendeu no contato (via e-mail/ jun. 2016) com dez professores que atuam na formação docente, resultou no retorno de seis questionários. Entende-se que o questionário, por ser um instrumento que demanda tempo por parte dos participantes, também expõe o sujeito participante, podendo influenciar ou até mesmo limitar o número de envolvidos.

Entre os aspectos gerias que definem o perfil dos participantes, evidencia-se que são vozes marcadas pela experiência profissional, oscilando entre o maior tempo no ensino de língua alemã correspondente a trinta e dois (32) anos e doze (12) anos como menor tempo de atuação na área. Também todos os professores possuem uma formação acadêmica específica na área. Além disso, essas vozes retratam a realidade do ensino de língua alemã no ensino superior, visto que houve retorno de questionários proveniente das regiões Nordeste, Sudeste e Sul, especificamente de cinco estados (CE, RJ, PR, SC, RS). Ainda os participantes informaram que o tempo de adoção do material $D a F$ kompakt numa instituição é de cinco anos e um semestre numa outra instituição.

A partir dessas delineações, seguem algumas considerações gerais sobre os três livros didáticos de ensino e aprendizagem de língua alemã, voltados para aprendizes iniciantes, que conforme o Quadro Europeu Comum de Referência para Línguas, inserem-se no nível básico (A1) ${ }^{6}$.

\footnotetext{
${ }^{6}$ As obras didáticas publicadas a partir de 2001 estão pautadas no Quadro Europeu Comum de Referência para Línguas definido pelo Conselho da Europa, cujo objetivo está em fornecer uma base comum para o planejamento de curso de idiomas, a partir de seis níveis de aprendizagem (o nível A1- básico até o nível C2 - avançado); da elaboração de exames; assim como da produção de materiais de ensino. Disponível em: $<$ http://languagesapprentice.wordpress.com/2012/09/30/quadro-europeu-comum-de-referencia-para-linguas/ $>$ Acesso em: 20 ago. 2015.
} 


\section{Caracterização dos livros didáticos de língua alemã: aspectos gerais}

Em relação ao livro didático DaF kompakt (SANDER et al., 2011), vale ressaltar que se destina para iniciantes adultos (Deutsch als Fremdsprache für Erwachsene) e que conduz os aprendizes, num único volume, aos conhecimentos linguísticos e socioculturais do nível A1 ao nível B1. Em termos estruturais, o livro DaF kompakt Al contém oito lições, sendo que essas lições são fragmentadas em três sublições, quer sejam em três partes, que apresentam uma temática relacionada ao tema gerador. Assim por exemplo, na primeira lição consta a temática do "Eu e os outros" (Ich und die anderen) e compreende a parte A, com o título "Bom dia!" (Guten Tag!), a parte B, com o tema "Me alegra" (Freut mich!) e a parte C, intitulada "Burocracia de A a Z" (Burokratie von A bis Z).

As lições contemplam oito temas principais, que são: informações sobre si mesmo e sobre os outros; agenda e organização do horário; empresa familiar; atividades de lazer e diversão; moradia; vestuário e novos amigos; cumprimentos no contexto da Suíça; e alimentação. Dentro dessa organização constam os aspectos gramaticais, as estruturas linguísticas, o vocabulário, sendo alternadas as habilidades comunicativas, iniciando-se pela audição, seguido da escrita.

No que diz respeito à apresentação do studio d (FUNK et al., 2013), a obra didática é composta por três livros, os quais compreendem os níveis A1, A2 e B1. Studio $d$ disponibiliza para cada nível de ensino, um livro composto pelo livro texto (Kursbuch A1) e livro de exercícios (Übungsbuch A1). Esse material oferece doze (12) unidades com uma progressão temática e gramatical, sendo que nessa organização composicional, o livro, inicialmente traz uma unidade intitulada 'Começar o alemão' (Start auf Deutsch) que contém oito páginas e quatro subdivisões, sendo sequenciadas pelas unidades (espécie de blocos, formados por quatro lições e/ou unidades), demonstrando uma estrutura fixa.

Ao final de cada bloco, quer seja, após quatro unidades, segue uma parte que é chamada de estação; assim o livro tem a Station 1, Station 2 e a Station 3. Nessas estações, o aprendiz ao fazer as paradas, depara-se com materiais que oportunizam a revisão, o aprofundamento e a avanço do conteúdo programático desenvolvido nas diferentes unidades. Studio $d$ contempla doze lições que trabalham temas, como primeiros contatos, pontos turísticos e línguas na Europa, países e pessoas, compromissos e horários, profissões e rotina, férias e viagens, comidas e bebidas, vestuário e tempo saúde, festividades, dentre outros. Nessa organização estrutural são abordados e trabalhados diversos textos, a gramática, os aspectos culturais, o vocabulário, os atos de fala e a fonética.

Em relação ao terceiro livro que compõe o corpus da pesquisa, está a coleção didática denominada Menschen: Deutsch als Fremdsprache, (GLAS-PETERS et al., 2012). Esse material didático se destina a jovens e adultos aprendizes de língua alemã como língua estrangeira e, apesar de estar dividida em três níveis (A1, A2, B1), cada nível depreende duas etapas distintas, como A1.1 e A1.2, assim como apresenta dois livros, o livro texto (Kursbuch A1.1) e o livro de exercícios (Arbeitsbuch A1.1).

O livro didático Menschen A1.1 contém doze (12) lições curtas, que são agrupados em quatro módulos, cada um com três lições. Cada lição é organizada em diferentes etapas, que, de certa forma, apresentam uma estrutura fixa. Sendo assim, cada lição ocupa quatro páginas do livro e seguem uma estrutura transparente e repetitiva, iniciando-se pela página de abertura/entrada (die Einstiegsseite), seguida pela página dupla (die Doppelseite) e, finalizando a lição com a página final (die Abschlussseite); sendo que após cada módulo, no caso três etapas, o livro inclui quatro páginas 
adicionais (die Zusatzseiten). É na seção da página dupla, visto serem duas páginas da lição, que são apresentados e trabalhados os conteúdos centrais, quer sejam as estruturas linguísticas e gramaticais.

As lições abordam diferentes temáticas, tais como: informações pessoais, profissões, utensílios domésticos, tecnologias de informação, família, idiomas, países e pessoas, atividades de lazer, comidas e bebidas, viagens, rotinas de trabalho, festividades, dentre outros.

Dessa forma, os três livros didáticos, no que se refere à apresentação e descrição, possuem diversos recursos que contribuem no processo de ensino e aprendizagem (enquanto material didático). Além disso, eles procuram preparar os aprendizes de alemão como língua estrangeira do nível A1 até nível B1 do Quadro Europeu Comum de Referência para Línguas.

\section{Discussão dos dados: análise de aspectos socioculturais e discursivos}

A partir dos objetivos propostos, que consistem em (i) identificar os aspectos socioculturais que subjazem os três livros didáticos adotados na formação de professores de língua alemã, destacando em que medida contemplam a realidade linguística e sociocultural de outros contextos e (ii) analisar as vozes de professores/usuários de livros didáticos, no sentido de compreender em que medida seu discurso tem repercussão na constituição e no papel desses materiais, seguem algumas discussões com base nesses objetivos.

\subsection{Foco nos aspectos socioculturais}

A análise de elementos relativos à sociedade e à cultura dos falantes de língua alemã, está baseada em alguns excertos, nos quais se verifica que os livros didáticos contemplam esses aspectos, no sentido de mostrar formas diferentes de significar o mundo.

Pode-se, nesse sentido, destacar o emprego dos sobrenomes, que consta no material didático Menschen, ao apresentar a situação intitulada "Conversa ao telefone" (Am Telefon). Trata-se de um exercício de recepção e produção de texto oral, no qual o aprendiz procura identificar, entender e elencar as formas de atender uma ligação telefônica no contexto de falantes do idioma alemão.

Essa estratégia pedagógica mostra um aspecto da cultura-alvo, pois destaca que os sobrenomes são usados com muita frequência dentre os falantes de alemão, o que, para o aprendiz brasileiro caracteriza-se como um aspecto diferente, até mesmo estranho, já que para a cultural nacional, as pessoas empregam o primeiro nome nas interações verbais.

Especificamente no exemplo referido, o aprendiz precisa interagir com outras pessoas e, ao simular uma conversa telefônica e atender o telefone, deve pronunciar o sobrenome. Vale ressaltar que, o material didático Menschen procura chamar a atenção para essa especificidade, bem como nesse mesmo exercício requer dos estudantes a informação de como se atende o telefone em outros países (Wie meldet man sich in anderen Ländern am Telefon?).

Nessa mesma proposta, num outro exemplo, o material propõe uma produção de texto oral, em que se solicita do aluno, após ter aprendido como se despede numa conversa ao telefone, que informe as formas de despedidas usuais na sua língua materna (Wie verabschiedet man sich in Ihrer Muttersprache?). Também o exercício propõe que o aprendiz procure traduzir as expressões idiomáticas da língua-alvo para a sua língua 
materna. Nessa atividade, especificamente, há uma preocupação em contemplar a realidade linguística e sociocultural de outros contextos. Uma vez que o material propõe que o usuário/aprendiz estabeleça uma relação com o contexto linguístico materno.

A questão do uso dos sobrenomes pelos falantes da língua alemã também é um aspecto cultural destacado no material studio $d$ em suas primeiras páginas, constando como primeiro texto. Especificamente, o livro apresenta uma lista de sobrenomes, no caso os dez sobrenomes mais conhecidos e adotados, como diz o enunciado, são os "Top 10". Dentre esses estão, por exemplo, Müller, Schneider, Becker, Schmidt e Fischer. Também é solicitado que o aprendiz informe quais são os sobrenomes mais adotados na sua cultura (Und bei Ihnen?). Isso pode ser visualizado na figura seguinte (Figura 1).

Figura 1 - Os sobrenomes (FUNK et al., 2013, p. 13).

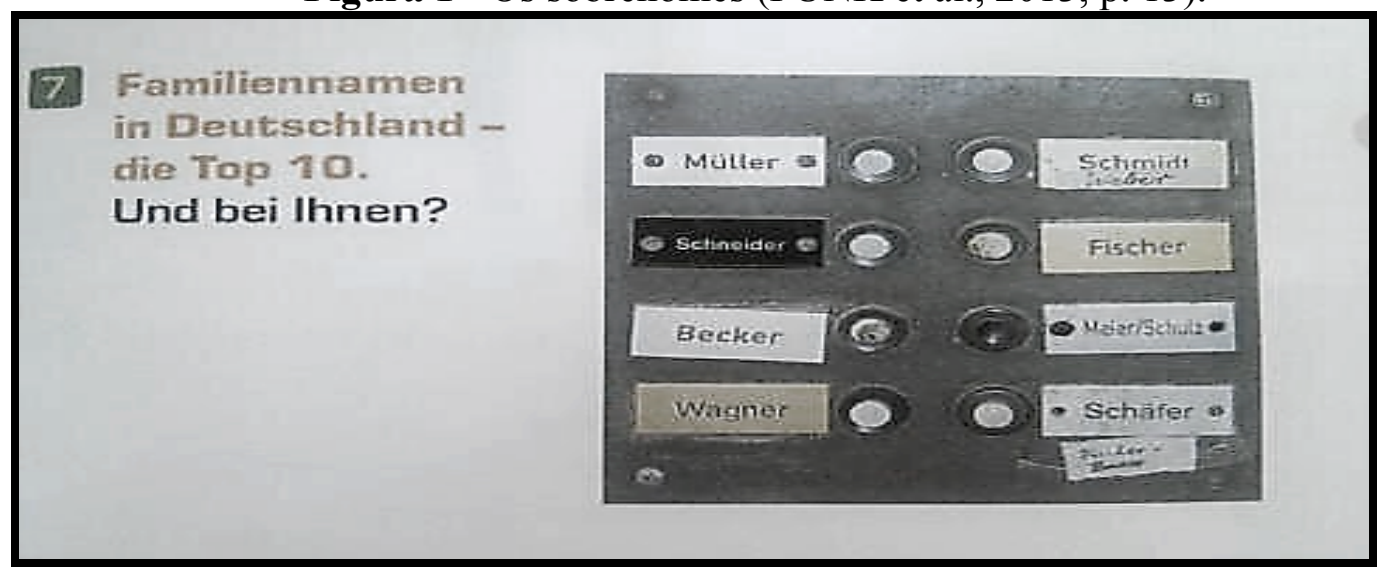

Nesse exemplo (Figura 1), temos uma questão muito singular da cultura na Alemanha, aspecto esse que não é usual para o contexto brasileiro. O texto procura representar uma característica da sociedade e da cultura, especificamente, o hábito dos alemães escreverem seus sobrenomes em condomínios para identificarem suas residências. Assim, não constam números ou outros símbolos e, sim os seus nomes, que identificam os moradores aos serem procurados por outros. Isso também pode revelar outra particularidade do comportamento e da cultura dos alemães, quer seja, o fato de serem pessoas que não mudam com frequência de moradia e não terem receio de socializar essa informação aos outros, mesmo às pessoas desconhecidas.

Esse aspecto, todavia, não está sendo problematizado no livro didático, pois o fato é apresentado de forma naturalizada, como uma convenção sociocultural. Ressaltase, dessa forma, a importância de nas aulas de línguas estrangeiras haver espaço para questionamentos, tais como: (i) Por que o livro didático traz esse texto?; (ii) Como compreendemos isso?; (iii) Será que isso é usual nesse contexto sociocultural? Por quê; (iv) Esse aspecto causa estranhamento para estudantes brasileiros?; dentre outras perguntas que possam estimular a reflexão e a sensibilização em relação ao outro. Tratase da necessidade de se trazer para as aulas de língua estrangeira, uma abordagem dos aspectos socioculturais, com o objetivo de motivar os aprendizes a refletirem sobre a cultura do outro (das Fremde/das Anrede) e a sua própria cultura (das Bekannte/das Eigene).

Também o livro studio $d$ apresenta textos, intitulados Landeskunde, que remetem aos aspectos culturais. Nesses textos, que são no total seis, são abordados os seguintes temas: a cidade de Frankfurt e seus pontos turísticos, o Euro e os países da União Europeia, o Departamento de Registro para Cidadãos Alemães e Estrangeiros, Horário de Refeições na Alemanha, Seguro de Saúde e Agência de Emprego. Para 
ilustrar isso, apresenta-se, conforme figura posterior (Figura 2), o texto sobre a temática da agência de emprego.

Figura 2 - Aspectos culturais (FUNK et al., 2013, p. 117).

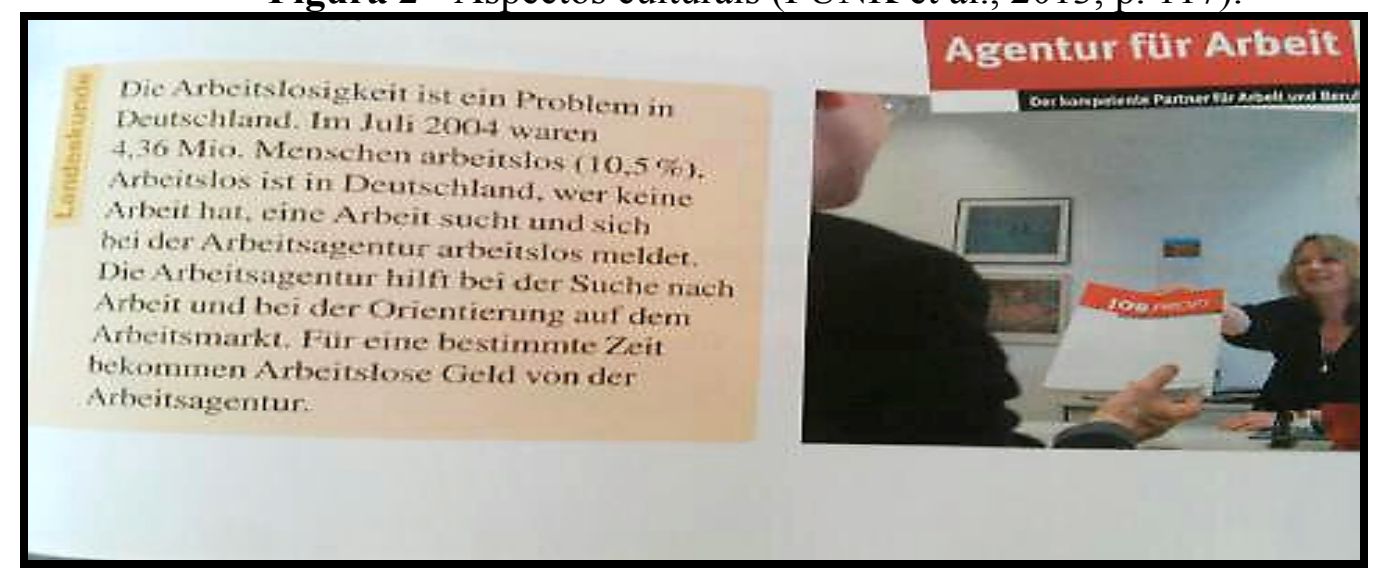

Nesse texto ${ }^{7}$, constam informações sobre uma questão vigente na Alemanha o desemprego. Para tanto, o texto notifica que se trata de um problema e apresenta a quantidade de desempregados no ano de 2004. Ao mesmo tempo, explica o que significa ser desempregado na Alemanha, assim como versa sobre o papel da agência do trabalho para quem procura trabalho.

O livro didático, ao trazer essa problemática, se distancia do modelo de materiais didáticos como se fossem cartões postais idílicos do país da língua-alvo (BOHUNOVSK, 2005; BOLOGNINI, 1991). Pois para essas autoras, os livros didáticos, em sua maioria, procuram vender uma imagem extremamente positiva da cultura e do país-alvo, através da amostra de imagens com ambientes perfeitos, sem problemas, semelhante a um verdadeiro paraíso social. Apesar disso, essa temática também pode ser debatida e relacionada com outros contextos socioculturais, no sentido de isso acontece em diversas sociedades, assim como na Alemanha, um país conhecido como sendo do Primeiro Mundo.

Nesse sentido, a realidade é dinâmica e determinados problemas são de caráter universal, sendo em alguns contextos socioculturais mais acentuados e em outros, nem tanto. Novamente compreende-se a importância de o professor nas aulas de língua estrangeira discutir essas questões, como o trabalho e o desemprego, mediante pesquisa em outros suportes, bem como na busca por dados atuais.

Além disso, esse mesmo material didático, expõe uma atividade de leitura e compreensão oral sobre morar de forma intercultural. Nesse exemplo, o enunciado declara que o senhor Hayashida, de origem étnica japonesa, reside na Alemanha. Também há o questionamento acerca do que ele infere sobre morar nesse país. Isso podemos identificar na ilustração próxima (Figura 3).

\footnotetext{
${ }^{7} \mathrm{O}$ texto destaca que o desemprego é um problema na Alemanha. Em julho de 2004 eram 4,36 milhões. Pessoas desempregadas (10,5\%). Desempregado na Alemanha é quem não tem emprego, quem não procura um trabalho e quem informa que está sem emprego na agência do trabalho. A agência do trabalho auxilia na procura por um trabalho e na orientação quanto às oportunidades de trabalho. Por um certo tempo, os desempregados recebem dinheiro da agência (FUNK, et al., 2013, p. 117 [tradução minha]).
} 
Figura 3 - Morar entre culturas (FUNK et al., 2013, p. 72).

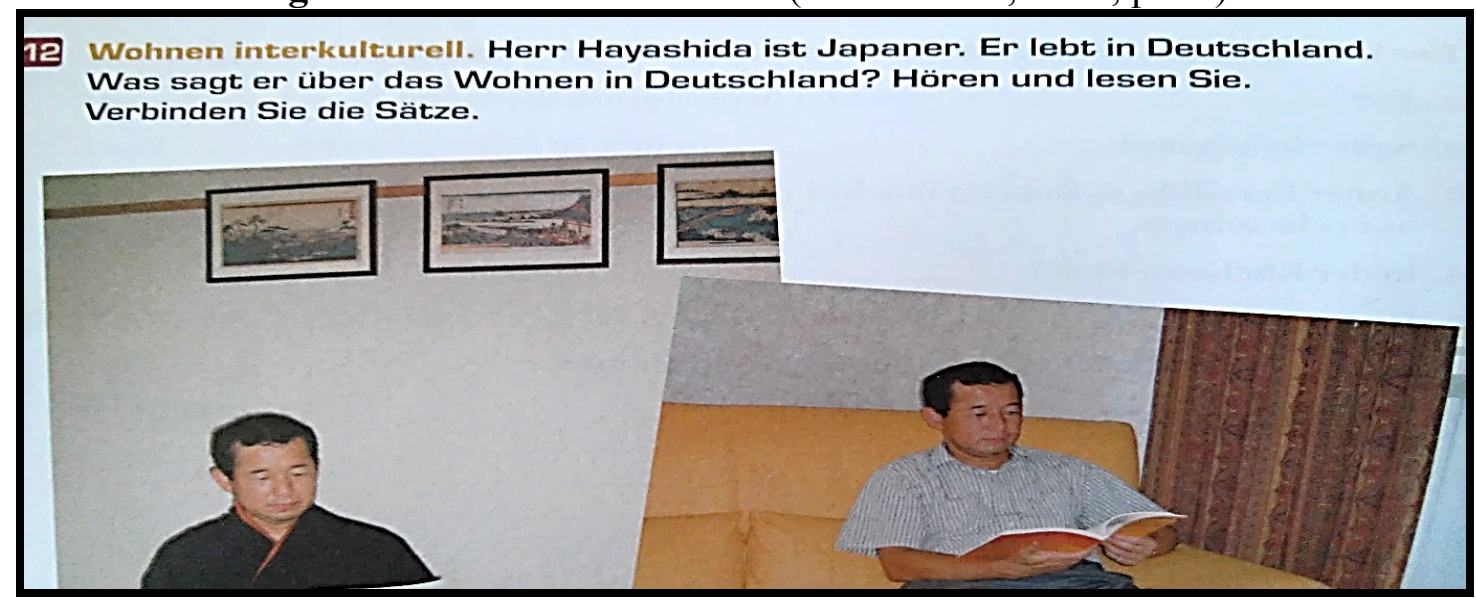

Aqui, além da linguagem verbal, temos o recurso das imagens, que procuram demonstrar os aspectos culturais no tocante à moradia na Alemanha e no Japão. Como a linguagem não-verbal evidencia, a abordagem intercultural fica mais no nível da comparação entre culturas. Quer dizer, o texto expõe alguns aspectos, conforme o ponto de vista do narrador, positivos e outros entendidos como negativos quanto à moradia na Alemanha e no Japão, assumindo um discurso imparcial.

Conforme Tilio (2008), os livros didáticos de língua estrangeira, ao tratarem de questões culturais, o fazem de forma cuidadosa para não gerarem polêmica ou discussão. Para ele, esses materiais "não tratam de cultura seriamente, ou seja, de forma a levar os alunos a pensar criticamente" (TILIO, 2008, p. 138). Dessa forma, a abordagem das questões culturais, na maioria dos livros, implica falar dos hábitos, costumes e comida do grupo cultural da língua-alvo. É o que a ilustração seguinte (Figura 4) procura explicitar.

Figura 4 - O churrasco (SANDER et al., 2011, p. 60).

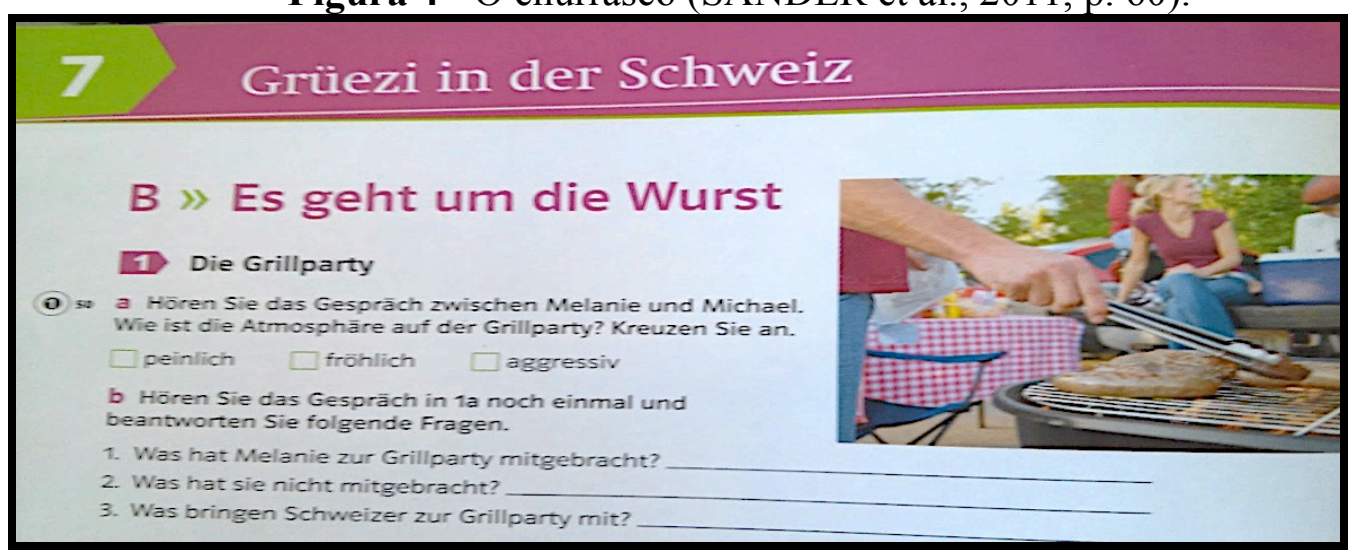

O livro didático DaF kompakt ilustra uma situação típica dos alemães, os quais gostam de aproveitar os dias de temperaturas mais amenas, para se reunirem em espaços livres, como nos parques e fazerem atividades em conjunto, dentre esses um churrasco entre amigos. Aqui, conforme informa o enunciado, trata-se da salsicha (Es geht um die Wurst).

O evento de fazer churrasco numa grelha depreende algumas convenções socioculturais, no sentido de que, como ele é feito numa churrasqueira portátil e não há um espaço específico na casa das pessoas para se fazer o churrasco; os ambientes 
externos (jardins, pátios, parques, áreas verdes) são os mais usados. Costuma-se fazer carne de porco, frango, bifes, além dos vários tipos de linguiças e salsichas na grelha. Vale destacar que, nas residências dos alemães não se encontra um local - uma churrasqueira - para se fazer o churrasco, como é usual no contexto brasileiro, sobretudo nos estados sul-brasileiros.

Além disso, não é necessário ter muito planejamento para fazer um churrasco, basta juntar os amigos, sendo que, para tanto, cada pessoa leva o que vai consumir. Isso significa que, a menos que o organizador do churrasco deixe explícito que irá se responsabilizar pelos alimentos de todos (o que não é usual), espera-se que cada participante traga sua própria comida e bebida. Dessa forma, fica estabelecido que ninguém precisa pensar nas necessidades e desejos dos outros.

Ao mesmo tempo, como cada integrante providencia sua carne, necessariamente, não haverá desperdício de alimentos. Além disso, tem um aspecto econômico, pois a carne na Alemanha, na Suíça e nos países europeus é cara. Enfím, é uma oportunidade de encontrar os amigos, interagir e confraternizar, sendo que, enquanto alguns cuidam da churrasqueira, os outros conversam distraidamente, conforme podemos visualizar na ilustração anterior (Figura 4).

Considerando esses aspectos socioculturais, o livro, no capítulo sobre a Suíça, apresenta essa situação, sendo que o aprendiz (alternativa a) é convidado a ouvir um diálogo entre a Melanie e o Michael e depreender como está o clima na churrasqueira: se está embaraçoso, alegre ou agressivo. E na alternativa $b$, o aprendiz, com base na compreensão auditiva, informa o que a Melanie trouxe para o evento do churrasco, $o$ que ela não trouxe e o que os suíços trazem para uma festa na grelha.

Nesse sentido, o texto destaca essa particularidade da cultura alemã, que quando se é convidado para um churrasco, cada pessoa traz a sua linguiça - o que para outros contextos, sobretudo o brasileiro, não é usual, podendo causar estranhamento, assim como choque entre culturas.

Nesse exemplo em questão (Figura 4), uma das participantes (Melanie) não levou a sua comida para a festividade junto à grelha, apenas levou uma flor; assim, ela se sentiu, inicialmente, numa situação de desconforto, desajuste sociocultural, ou como ela descreve, uma situação embaraçosa. Sendo que esse conflito foi resolvido, pois ela recebeu uma linguiça do seu amigo Michael.

Ainda, é considerado adequado, no caso de ser convidado para um evento, um jantar, uma festividade, que o convidado leve algum presente para o anfitrião e, sobretudo, compareça no horário marcado, observando a pontualidade (não chegar antes e nem depois).

Novamente a importância de se considerar que num contexto de ensino de língua estrangeira, os alunos são oriundos de diversas partes do mundo e, dessa forma "trazem o seu próprio ponto de vista sobre fenômenos e eventos no âmbito da línguaalvo" (RÖSLER, 2012, p. 82). Pois, conforme a participante declara: Outros países outros costumes, hábitos e condutas (Andere Länder - andere Sitten).

Em partes, pode-se inferir que, mesmo não contemplando a realidade linguística e sociocultural de aprendizes brasileiros do idioma alemão, os materiais didáticos evidenciam, em determinados momentos, abertura para outros contextos linguísticos e socioculturais. Por outro lado, entende-se que esses livros didáticos poderiam sugerir ainda outras estratégias de ensino e aprendizagem, exercícios, imagens, assim como sugestões de leituras e temáticas com intuito de iniciar e/ou avançar na discussão das diferenças linguísticas e culturais, procurando, sensibilizar os aprendizes para com o outro. Dessa forma, ressalta-se a necessidade de um ensino e 
aprendizagem de cultura, que procure não aprender sobre a cultura do outro e, sim aprender a partir do encontro das culturas envolvidas; nesse caso, a brasileira e a alemã.

\subsection{Foco nos aspectos discursivos}

O processo de análise discursiva tem a pretensão de interrogar os sentidos estabelecidos em diversas formas de produção, que podem ser verbais e não verbais, bastando que sua materialidade produza sentidos para interpretação. Conforme Rodrigues, a proposta metodológica consiste na "construção do analista como princípio norteador colocar questões e a problematização no confronto com os dados, o que leva a considerar a possibilidade de abstração metodológica como resultado analítico" (RODRIGUES, 2010, p. 67),

No que diz respeito às questões específicas sobre o livro didático de ensino de língua alemã (cf. Parte $\mathrm{B}$ do questionário - ver apêndice 1), com relação à questão 1 , os professores definiram o livro didático de língua alemã de sua instituição e seu papel no contexto socioeducativo brasileiro de maneiras distintas.

O professor A destacou que o livro DaF kompakt é um método de abordagem comunicativa com grande variedade de atividades e apelo visual como todos os métodos atuais. O professor B afirmou ser o livro didático Menschen um material de apoio e um guia de cultura da língua e país de origem. Já, outro participante (professor C) destaca que o livro Menschen foi feito para um público mundial, visando aproximar a língua e a cultura alvo do público. O professor D reitera que o livro desenvolve a competência linguístico-comunicativa e também intercultural dos aprendizes, assim como auxilia na formação linguística de seus licenciandos (futuros professores), sendo o material didático material de ensino base, porém não exclusivo.

Da mesma forma, professor E define o livro didático como uma tentativa de aproximar o aluno a diversos contextos culturais, onde usará os elementos linguísticos estudados, e seu papel no contexto socioeducativo depende muito da metodologia do professor com a qual aplica o livro. E, por último, o professor $\mathrm{F}$ destaca que o livro didático é adotado nos primeiros semestres do curso, por acharem importante que o aluno, primeiramente, aprenda a língua e, posteriormente, se aprofunde nas questões mais relativas ao funcionamento da língua e à sua didática específica. Para esse participante, o papel do livro didático consiste em auxiliar o docente na tarefa de uma demanda inicial de aprendizado de língua.

$\mathrm{Na}$ pergunta seguinte, os participantes responderam ao questionamento se o livro pode ser considerado adequado à realidade sociolinguística e cultural do aprendiz brasileiro. Para tanto, o professor A enfatiza que nenhum material é muito adequado à realidade brasileira e nunca será. O professor B destaca que como a maioria dos livros didáticos adotados no Brasil é elaborada na Alemanha, hoje também na Áustria ou Suíça, eles são destinados aos mais diferentes países, com costumes e, inclusive, crenças das mais variadas. Sendo assim, sempre há partes em que o professor precisa fazer adaptações para trabalhar de modo que atenda à realidade sociolinguística e cultural do aprendiz brasileiro.

Já, o professor $\mathrm{C}$ afirma que os livros adotados não levam em consideração as particularidades sociolinguísticas e/ou culturais do Brasil. O professor D enfatiza que os materiais precisam de adaptações à realidade sociolinguística e cultural de nosso aprendiz e o participante E destaca que nenhum livro didático pode adequar-se totalmente à realidade sociolinguística e cultural do aprendiz da língua estrangeira. Ainda, o professor $\mathrm{F}$ menciona que, no caso de o livro didático considerar a realidade do aluno brasileiro, nenhum livro o faz. Dessa forma, a maioria afirmou que os materiais 
por eles adotados, não contemplam a realidade sociolinguística e cultural do aprendiz brasileiro, sendo necessário que o professor faça essa mediação.

Já na pergunta de número 3 , todos os professores manifestaram participar do processo de escolha do livro didático na sua instituição, inclusive alguns manifestaram serem condutores das discussões.

Em relação à pergunta seguinte, que explica o motivo específico pelo qual foi adotado esse material e se existe influência de alguma editora quanto a adoção do livro didático na sua instituição, o professor $\mathrm{A}$ destacou que o método anterior não atendia às necessidades dos alunos e estava defasado em termos culturais e que não houve influência de editoras. O professor B salientou que a editora influencia na escolha do livro didático; já, o professor $\mathrm{C}$ respondeu que o livro foi escolhido pelos colegas, e que neste caso, aconteceu grande influência da editora. O professor D destacou que o livro foi adotado porque se queria que os estudantes conseguissem alcançar mais rapidamente competência linguístico-comunicativa. Em relação a essa questão, o professor E destaca que o livro foi adotado por sua oferta de metodologia para aulas para adolescentes e, principalmente, para adultos e que não houve influência de alguma editora. E, por último o professor F enfatizou que o livro (referindo-se ao DaF kompakt) foi adotado recentemente por ser um material com uma progressão rápida, e por ser empregado em outras Universidades; assim como a editora foi fator de influência: primeiro por ser uma grande editora (o que garantiria a distribuição do material nas livrarias) e segundo pelos benefícios propostos (exemplares gratuitos, possibilidade de seminários).

$\mathrm{Na}$ pergunta sobre qual ser a proposta metodológica e a concepção de língua/cultura que subjaz o livro didático adotado pelo seu curso de formação de professores de língua alemã, o professor A destacou que a proposta metodológica requer um livro que seja bom em informações culturais do dia a dia alemão que tenha textos sobre os mais diversos temas, como o sistema educacional alemão, a universidade, o sistema de transporte, o supermercado, o sistema de atendimento médico, dentre outros. $\mathrm{O}$ professor $\mathrm{B}$ enfatizou que é aquela que visa atender todas as quatro habilidades, sendo transparente e objetivo. $\mathrm{O}$ professor $\mathrm{C}$ destacou que o livro apresenta uma língua e uma cultura homogeneizada, sem diferenças regionais e/ou sociais, sendo que o foco é o uso comunicativo da língua, em situações reais de uso da língua.

O professor seguinte destacou que o livro tem uma proposta metodológica orientada para situações relacionadas a necessidades comunicativas em situações cotidianas que podem surgir em países de língua alemã. E através dessas situações, os aprendizes são levados também à comparação cultural. Há também a apresentação de temas, nos quais estereótipos e clichês são trabalhados, sendo que, no entanto, uma fase de reflexão (para além da mera comparação), com a finalidade de fomentar o desenvolvimento de uma consciência e competência intercultural por parte do aluno, fica mais cargo do professor do que do livro didático. E, o professor E esclareceu ser a proposta metodológica comunicativa e intercultural. Ainda, o professor $\mathrm{F}$ mencionou que o livro segue a concepção $\mathrm{DACH}(\mathrm{L})^{8}$, sendo bastante comunicativo, porém ressalta a escrita também em primeiro plano (o que para sua instituição é importante). Também ressalta que a proposta metodológica é de ser compacto, ou seja, tem uma progressão bastante íngreme, pois busca o aprendizado rápido, intensivo - exatamente o que buscam na universidade.

No tocante ao questionamento de número 6 , no qual se indaga em que medida contempla (ou não) as diferentes comunidades falantes da língua alemã, os professores participantes destacaram que, em sua maioria, os livros atendem essa particularidade.

\footnotetext{
${ }^{8}$ A concepção de $\mathrm{DACH}(\mathrm{L})$ remete ao fato do livro, apesar de fazer uso da variedade padrão (alemão Standart), também contemplar outras variedades dialetais, no caso o alemão falado na Alemanha, Áustria, Suíça e Liechtenstein.
} 
Apenas um professor (participante C) manifestou que se tematiza muito pouco as diferentes comunidades falantes do alemão, e se restringem somente às diferenças vocabulares. E o professor D complementou enfatizando que os países de língua alemã são contemplados em DaF kompakt, há lições que se dedicam exclusivamente à Áustria, à Suíça e Liechtenstein. Isso acontece, no entanto, mais no plano do vocabulário, de informações culturais de cunho factual, apesar de haver também alguns temas de cunho intercultural. A abordagem dos países de língua é algo bem geral, não contemplando especificidades de determinadas comunidades falantes da língua-alvo. Da mesma forma, o professor F reitera que o livro por ser um DACH(L)-Lehrwerk, parece contemplar a Alemanha, Áustria, Suíça e Liechtenstein, sendo que ilhas linguísticas fora desse espaço da Europa Central não aparecem - como também é o caso em outros livros disponíveis no mercado.

Na pergunta de número 7, os professores responderam sobre como podem ser categorizados os textos presentes no livro didático por eles adotado. Para tanto, o professor A salienta que os textos em geral dão apoio aos diversos exercícios de compreensão oral e o professor B destaca que, de modo geral são textos muito curtos. Já, o professor $\mathrm{C}$ que há uma grande variedade de gêneros textuais, contemplando diversos usos e que há um enfoque em textos mais breves e multimodais.

No entendimento do professor D, o livro apresenta textos de diversos gêneros, como pequenas publicidades, anúncios e artigos de jornal, e-mails, entrevistas. Esse professor ressalta também que muitos desses textos são adaptados ao nível do aprendiz. Dessa forma, pode-se dizer que textos autênticos são pouco contemplados nos referidos materiais. O professor $\mathrm{E}$ salienta que os textos são apresentados, conforme $\mathrm{o}$ assunto/contexto abordado, por gêneros textuais, por exemplo carta, cardápio, mapa, dentre outros. E o último participante menciona que há uma grande predominância de $e$ mails e textos informativos não autênticos, o que para ele é um dado negativo.

$\mathrm{Na}$ pergunta final, os professores elencam as vantagens no uso do livro didático e destacam as desvantagens quanto a adoção desse material. Nesse sentido, o professor A considera como vantagem a ênfase na compreensão oral e o professor B destaca que as vantagens são que o livro é um apoio, pois apresenta uma sequência gramatical e vocabular, assim os alunos podem se familiarizar com os países de origem da língua alemã. Esse mesmo professor também elenca algumas desvantagens, como a tendência de seguir com muito rigor o livro didático, enquanto se poderia trabalhar com outros materiais mais inspiradores e atraentes. $\mathrm{O}$ professor $\mathrm{C}$ concebe como vantagem a possibilidade para o discente de ter material à disposição que o acompanhará e o apoiará no seu aprendizado, em contrapartida a maior desvantagem é a homogeneização linguística.

Para o professor D o livro didático representa um material de ensino que foi produzido com uma base teórica específica, isto é, contemplando uma determinada visão de língua e de ensino-aprendizagem, tem uma organização estruturada, seguindo uma progressão de vocabulário e estrutura. Essas são as vantagens, segundo ele. Por outro lado, o material didático dirige-se a um público-alvo possível, não real. Sendo assim, a principal desvantagem de um material didático é não contemplar as necessidades e especificidades de seu público-alvo real e do contexto de ensinoaprendizagem da língua-alvo. Tais lacunas precisam, assim, ser supridas pelo professor, no caso da adoção de um livro didático. O professor E entende que sempre há vantagens e desvantagens de livros didáticos, pois não existe nenhum perfeito. Depende muito do professor e da turma, o que faz com essa oferta de textos e exercícios. Já, o professor $\mathrm{F}$ menciona não poder ainda ter essa dimensão, pois a adoção do livro é muito recente na instituição. 
De acordo com as vozes discursivas desses professores, alguns elementos merecem destaque, como no tocante à adequação dos materiais didáticos ao contexto brasileiro. Nesse sentido, mesmo alguns manifestando ser necessário adaptações nos materiais para que se possa atender à realidade sociolinguística e cultural do aprendiz brasileiro, a maioria dos professores manifestou-se contrariamente, inclusive afirmando que nenhuma obra contempla as particularidades sociolinguísticas e/ou culturais brasileiras.

Também houve convergência no discurso dos professores sobre os materiais considerarem as diferentes comunidades falantes da língua alemã, pois segundo eles, os livros atendem essa particularidade, que, no entanto, restringe-se mais aos países da Alemanha, Áustria, Suíça e Liechtenstein.

Ainda quanto à categorização dos textos nos livros, as vozes desses professores, também, expressam posicionamentos similares. Uma vez que elas inferem que nos materiais consta uma grande variedade de gêneros textuais, com destaque para o e-mail, sendo que os textos autênticos são pouco contemplados nos referidos materiais.

Já, as vozes dos professores manifestaram discursos divergentes quanto à proposta metodológica que subjaz ao livro didático adotado pelas suas instituições formativas. Umas vozes destacaram a importância do desenvolvimento das quatro habilidades comunicativas; outras destacaram a perspectiva intercultural, mesmo que seja mais na dimensão da comparação entre culturas, sem uma reflexão propriamente dita; e, ainda outros, destacaram a progressão íngreme e o aprendizado rápido, intensivo como a proposta metodológica do material adotado na universidade.

Ainda, a divergência do discurso dos professores manifestou-se quanto ao seu entendimento sobre as vantagens do livro didático. Para uns, isso insere-se no desenvolvimento da compreensão oral; outros consideram o livro um apoio para o ensino, pois apresenta uma sequência gramatical e vocabular; e ainda uns entendem o livro como um recurso na aprendizagem, visto que o aprendiz pode dispor de um material de apoio. Também nessas vozes encontram-se posicionamentos distintos acerca das desvantagens da adoção do livro didático. Para tanto, alguns professores destacam como a maior desvantagem, a homogeneização linguística; outros o fato que se tende a seguir com muito rigor o livro didático, enquanto se poderia trabalhar com outros materiais mais inspiradores e atraentes. $\mathrm{E}$, ainda alguns consideram uma desvantagem $\mathrm{o}$ fato de o livro voltar-se para um público-alvo não real, e não contemplar as necessidades e especificidades de seu público-alvo real.

Finalmente, outros sentidos que emergiram nas vozes dos professores dizem respeito à prática pedagógica, no sentido de que, mediante a adoção do livro didático, se faz necessário a mediação desse profissional, já que são fundamentais as adaptações constantes nesses materiais, para que se possa adequá-los ao contexto sociolinguístico e cultural brasileiros.

\section{Considerações finais}

Considerando as descrições, discussões e análises tecidas, reitera-se que o livro didático pode ser concebido como um gênero complexo e multifacetado, cuja constituição sociocultural e histórica é marcada por elementos gráficos e editoriais. Posto isso, a análise de livro didático deve considerar que esse objeto se trata de um produto de consumo, uma mercadoria, sendo que a comercialização e a distribuição do livro dependem da edição e do contexto socioeconômico e político. 
A posição assumida aqui advoga a favor dos livros didáticos como recursos valiosos, pelo fato de oferecerem insumos diversos, tanto para o ensino como para a aprendizagem da língua e da cultura a serem aprendidas. Sobretudo, pelo aspecto da pragmaticidade, porque na realidade educacional brasileira, mesmo no ensino superior, os materiais didáticos auxiliam na etapa de preparação e no planejamento do curso e das aulas, considerando o tempo, por vezes limitado, que o professor dispõe e/ou destina para execução dessa tarefa pedagógica.

Em contrapartida, não se concebe a adoção dos materiais didáticos como controladores, nem limitadores da prática docente. Ao contrário, reforça-se que toda teoria procede da prática de ensino e de aprendizagem e de que ambas são interelacionadas, o que capacita o profissional de línguas a pensar, criar e produzir seus próprios materias didáticos, visto estarem baseados na sua vivência e experiência profissional e, sobretudo, atenderem as particulariades sociolinguísticas e culturais dos seus aprendizes.

Finalmente retoma-se que a pesquisa não procurou apresentar um viés avaliativo sobre o objeto de investigação, mesmo fazendo uso dessa perspectiva, já que se configura como uma etapa quanto ao processo de entendimento do livro didático. Em contrapartida, propôs-se a investigar e a compreender o livro didático de língua alemã como língua estrangeira como uma fonte significativa na construção das práticas e dos saberes no contexto de formação docente no ensino superior brasileiro.

\section{REFERÊNCIAS}

ALMEIDA FILHO, José Carlos Paes de. Codificar conteúdos, processor, e reflexão formadora no material didático para ensino de línguas. In: LOPES PEREIRA, Ariovaldo; GOTTHEIM, Liliana. Materiais didáticos para o ensino de Língua Estrangeira: processos de criação e contextos de uso. Campinas, São Paulo: Mercado de Letras, 2013, p. 13-28.

BAKHTIN, Mikhail. O problema do texto na Linguística, na Filologia e em outras Ciências Humanas. In: Estética da criação verbal. Tradução: Paulo Bezerra. 4. ed. São Paulo: Martins Fontes, 2003[1979]. p. 307-335.

BOHUNOVSKY, Ruth. O imaginário (colonial) no ensino de alemão como língua estrangeira no Brasil. Trabalhos em Linguística Aplicada, Campinas, n. 44, p. 89-95, 2005.

BOLOGNINI, Carmen Zink. Livro didático: cartão postal do país onde se fala a línguaalvo? - Resenha Crítica. Trabalhos em Linguística Aplicada, Campinas, n. 17, p. 43$56,1991$.

FUNK, Hermann et al. Studio d: Deutsch als Fremdsprache A1. Kursbuch und Arbeitsbuch. München: Cornelsen Verlag, 2013.

GLAS-PETERS, Sabine et al. Menschen: Deutsch als Fremdsprache A1.1. Kursbuch und Arbeitsbuch. Ismaning Hueber Verlag, 2012.

MOITA LOPES, Luiz Paulo da. (Org.). Por uma Linguística Aplicada Indisciplinar. São Paulo: Parábola Editorial, 2006.

MUSSALIM, Fernanda. Análise do Discurso. In: MUSSALIM, Fernanda; BENTES, Anna Cristina (Orgs.). Introdução à linguística: domínios e fronteiras. São Paulo: Cortez, 2006, p. 101-142. 
ORLANDI, Eni Puccinelli. Discurso e texto: formulação e circulação de sentidos. Campinas, SP: Pontes Editores, 2008.

Editores, 2002.

Análise de Discurso: princípios e procedimentos. Campinas, SP: Pontes

PESSOA, Rosane Rocha. O livro didático na perspectiva da formação de professores.

Trabalhos em Linguística Aplicada. Campinas, n. 48, p. 53-69, Jan./Jun., 2009.

POSSENTI, Sírio. Teoria do discurso: um caso de múltiplas rupturas. In: MUSSALIM, Fernanda; BENTES, Anna Cristina (Orgs.). Introdução à linguística: domínios e fronteiras. São Paulo: Cortez, 2006, p. 353-392.

RODRIGUES, Marlon Leal. Discurso e metodologia: tensão na análise. Interface da Educ., Paranaíba, v.1, n.1, p. 66-82, 2010.

RÖSLER, Dietmar. Deutsch als Fremdsprache: eine Einführung. Stuttgart: Verlag J.B. Metzler, 2012.

SANDER, Ilse et al. DaF kompakt: Kursbuch und- Übungsbuch A1. Stuttgart: Klett Verlag, 2011.

SILVA, Renato Caixeta da. Estudos recentes em Linguística Aplicada no Brasil a respeito de livros didáticos de língua estrangeria. Revista Brasileira de Linguística Aplicada, Belo Horizonte, v. 10, n. 1, p. 207-226, 2010.

TILIO, Rogério. O papel do livro didático no ensino de língua estrangeira. Revista Eletrônica do Instituto de Humanidades, Campinas, SP, v. VII, n. XXVI, jul./set., p. 117-144, 2008.

UPHOFF, Dörthe. O poder do livro didático e a posição do professor no ensino de alemão como língua estrangeira. Campinas, 2009, 178f. Tese (Doutorado em Estudos da Linguagem) - Programa de Pós-Graduação em Linguística Aplicada, Universidade Estadual de Campinas/UNICAMP, Campinas - SP, 2009.

VON BORSTEL, Clarice N. A linguagem sociocultural do Brasildeutsch. São Carlos, SP: Pedro \& João Editores, 2011.

Recebido em: agosto de 2017.

Aprovado em: outubro de 2017.

Como citar este trabalho:

SCHMIDT, C. O livro didático de língua alemã no ensino superior brasileiro: análise de aspectos socioculturais e discursivos. Traços de linguagem, v. 1, n. 2, p. 9-26, 2017. 


\section{UNIVERSIDADE ESTADUAL DO OESTE DO PARANÁ \\ CENTRO DE EDUCAÇÃO, COMUNICAÇÃO E ARTES \\ CURSO DE PÓS-GRADUAÇÃO EM LETRAS}

\section{QUESTIONÁRIO - AVALIAÇÃO QUALITATIVA DO LIVRO DIDÁTICO}

\section{A - QUESTÕES DE IDENTIFICAÇÃO}

1. Nome do docente:

2. Formação profissional:

3. Tempo de atuação na área de língua alemã:

4. Nome do livro didático adotado:

5. Tempo de adoção do livro pela instituição:

\section{B - QUESTÕES SOBRE O LIVRO DIDÁTICO DE ENSINO DE LÍNGUA ALEMÃ}

1. Como você define o livro didático de língua alemã de sua instituição e seu papel no contexto socioeducativo brasileiro?

2. Pode-se considerá-lo adequado à realidade sociolinguística e cultural do aprendiz brasileiro?

3. Participa do processo de escolha do(s) livro(s) didático(s) na sua instituição de ensino?

4. Por qual motivo específico foi adotado esse material e existe influência de alguma editora quanto a adoção do livro didático na sua instituição? Se sim, justifique.

5. Qual a proposta metodológica e a concepção de língua/cultura que subjazem o livro didático adotado pelo seu curso de formação de professores de língua alemã?

6. Em que medida contempla (ou não) as diferentes comunidades falantes da língua alemã?

7. Como podem ser categorizados os textos presentes no livro didático adotado?

8. Seria possível elencar vantagens no uso do livro didático? E existem desvantagens quanto a adoção desse material? 